\title{
Association of Common Variants in eNOS Gene with Primary Open Angle Glaucoma: A Meta-Analysis
}

\author{
Yang Xiang, ${ }^{1}$ Yi Dong, ${ }^{1,2}$ Xuan Li, ${ }^{1,2,3,4}$ and Xin Tang ${ }^{1,2,3,4}$ \\ ${ }^{1}$ Clinical College of Ophthalmology, Tianjin Medical University, 4 Gansu Road, Tianjin 300020, China \\ ${ }^{2}$ Tianjin Eye Hospital, 4 Gansu Road, Tianjin 300020, China \\ ${ }^{3}$ Tianjin Key Laboratory of Ophthalmology and Visual Science, 4 Gansu Road, Tianjin 300020, China \\ ${ }^{4}$ Tianjin Eye Institute, 4 Gansu Road, Tianjin 300020, China
}

Correspondence should be addressed to Xin Tang; professortangtj@163.com

Received 22 February 2016; Accepted 12 April 2016

Academic Editor: Hermann Mucke

Copyright (C) 2016 Yang Xiang et al. This is an open access article distributed under the Creative Commons Attribution License, which permits unrestricted use, distribution, and reproduction in any medium, provided the original work is properly cited.

\begin{abstract}
Purpose. To clarify the association of endothelial nitric oxide synthase (eNOS) polymorphisms and primary open angle glaucoma (POAG). Methods. After a systematic literature search in the MEDLINE, EMBASE, and ISI Web of Science databases, all relevant studies evaluating the association between the polymorphisms (rs2070744 and rs1799983) of eNOS gene and POAG were screened and included. The pooled odds ratios (ORs) and the $95 \%$ confidence interval (CI) of each single-nucleotide polymorphism (SNP) in five genetic models were estimated using fixed-effect model if $I^{2}<50 \%$ in the test for heterogeneity; otherwise the random-effects model was used. Results. Thirty-one records were obtained, with five being suitable for meta-analysis. The overall results showed that both TT genotype in rs2070744 and GG genotype in rs1799983 are associated with decreased risk of POAG susceptibility. Stratified analysis based on ethnicity showed that the association of rs2070744 with POAG remained only in Caucasians. Results of subgroup analysis by sex indicated association between both polymorphisms and POAG in female group, but not in male group. Conclusions. TT genotype and/or T-allele in rs2070744, as well as GG genotype and/or G-allele in rs1799983, was associated with decreased risk for POAG overall and in female group.
\end{abstract}

\section{Introduction}

Glaucoma is a common, complex, heterogenous disease and it constitutes the major cause of irreversible blindness worldwide [1]. In 2013, the number of people (aged 4080 years) with glaucoma was estimated to be 64.3 million, increasing to 76.0 million in 2020 and 111.8 million in 2040, disproportionally affecting people residing in Asia and Africa [2]. Primary open angle glaucoma (POAG), the most common type of glaucoma in all populations, is characterized by progressive damage of retinal ganglion cells (RGCs) and their axons, leading to the pathognomonic remodeling of the optic nerve head and subsequent irrevocable vision loss [3]. The known risk factors for POAG include a higher age, African ancestry, refractive error, and a positive family history for glaucoma, apart from elevated intraocular pressure (IOP), an established risk contributor [4-6]. Furthermore, there is growing evidence that vascular [7, 8] and genetic [9-11] components may pose a potential risk to POAG patients, including both those with normal and elevated IOP.

Nitric oxide (NO) is an active biologic agent involved in diverse physiologic processes [12]. NO generated by endothelial nitric oxide synthase (eNOS) has been found to contribute to vasodilatation, increased local blood flow, and decreased vascular resistance in ocular circulation [13, 14]. Hence, changes in the activity of eNOS determined by genetic variations and environmental factors may play an important role in the pathogenesis of glaucoma. Several studies were conducted to evaluate the association of eNOS polymorphisms with risk of POAG but presented inconsistent results [15-20]. During seven functional single-nucleotide polymorphisms (SNPs) reported in relevant studies, the controversy was mainly centered on the two most important SNPs, T-786C (rs2070744) and Glu298Asp (rs1799983). Thus the current 
meta-analysis aims to assess the strength of the evidence for an effect of these two polymorphisms on POAG risk by combining data from all relevant eligible studies.

\section{Methods}

2.1. Literature Search. A systematic literature search was conducted in the MEDLINE, EMBASE, and Web of Science databases (accessed on November 30, 2015) with the following free words and MeSH terms: "glaucoma", "open angle", "Endothelial nitric oxide synthase", "eNOS", "polymorphism(s)", "single nucleotide polymorphism", and "SNP". We also supplemented our search by screening the reference lists of all the retrieved studies, as well as genome-wide association studies (GWAS) performed for glaucoma to which we have the access.

2.2. Inclusion and Exclusion Criteria. Eligible studies were included if they (1) evaluated the association between eNOS and POAG; (2) compared unrelated POAG cases and normal controls identified by complete ophthalmological examination in defined populations; (3) provided an odds ratio (OR) with $95 \%$ confidence interval (CI) in case and control groups, respectively, or other data which could be calculated to estimate an OR; and (4) were original research articles. All animal studies, case reports, abstracts from conferences, fulltexts with incomplete data, and reviews were excluded. As for duplicate studies retrieving data from the same source, ones with available data and the largest sample size were brought into the analysis list. Although we did not define language in the review process, the articles in the final analysis were all in English.

2.3. Literature Review and Data Extraction. Two investigators (Yang Xiang and Yi Dong) extracted data from the retrieved records and confirmed the validity of the included articles independently. The following variables were extracted: author, year of publication, ethnicity of subjects, demographic information, the numbers of cases and controls, results of Hardy-Weinberg equilibrium (HWE) test when reported, and the allele and genotype counts or frequencies of each SNP. When the allele or genotype counts were not given specially in some articles, they were calculated from the frequencies and then rounded to the nearest integer. A final review was performed by other reviewers (Xuan Li and Xin Tang) while the discrepancy was resolved through discussion.

2.4. Meta-Analysis and Test for Potential Bias. The Chi-square test was utilized to check whether the genotype distribution in controls was consistent with HWE for studies that did not report relevant data. To assess the strength of association between the polymorphisms (rs2070744 and rs1799983) of eNOS gene and POAG susceptibility, we estimated crude OR with its 95\% CI under allele model ( $T$ versus C, G versus A), homozygote model (TT versus CC, GG versus AA), heterozygote model (TC versus CC, GA versus AA), dominant model (TT + TC versus CC, GG + GA versus AA), and recessive model (TT versus $\mathrm{TC}+\mathrm{CC}$, GG versus GA + AA), respectively.

Interstudy heterogeneity was detected using the Chisquare-based $Q$ statistic test as well as the $I^{2}$ metric. If $P_{Q} \leq$ 0.10 or $I^{2}>50 \%$, which indicated significant heterogeneity in the comparison models among studies [21], the pooled ORs were calculated with a random-effects model (DerSimonian and Laird method) [22]. Otherwise, the fixed-effects model was considered more appropriate (Mantel-Haenszel method) [23]. We also conducted subgroup analysis based on ethnicity, as well as sex where applicable. Publication bias was investigated by Begg's tests and Egger's linear regression test [24, 25]. The statistical analysis was done with Stata 12.0 and the values of $P<0.05$ were considered statistically significant.

\section{Results}

3.1. Literature Search and Characteristics. The workflow and results of the literature review are shown in Figure 1. A total of thirty-one records were initially identified for the meta-analysis. Of the thirty-one, twenty-six studies were excluded due to duplicated publications, unsuitable titles or abstracts, or incomplete data. In total, five eligible studies [1519] were included and reviewed. Seven SNPs of eNOS gene, including rs2070744, rs1799983, rs743507, rs3793342, rs7830, rs11771443, and rs3918188, were evaluated for possible association with POAG while five SNPs, apart from rs2070744 and rs1799983, were reported in only one or two studies, the data of which were interpreted to be insufficient to perform a qualified meta-analysis. Consequently, the combined study population investigating rs2070744 (consisting of 1156 cases and 1879 controls) and rs1799983 (consisting of 1230 cases and 2035 controls) are involved in our meta-analysis, and the detailed characteristics of the included studies are listed in Tables 1 and 2 .

3.2. Meta-Analysis Results. Tables 3 and 4 show the summary results for the association between eNOS rs2070744 and rs1799983 and risk for POAG. Low heterogeneity was present among all the publications involved for all the genetic models (Tables 3 and 4). Thus, the data were combined using the fixed-effects model. For rs2070744, the data was pooled from 4 sample collections without HWE deviation, and the overall results showed significant association between rs2070744 and POAG $(\mathrm{OR}=0.736,95 \% \mathrm{CI}=0.594-0.912$ for $\mathrm{T}$-allele versus C allele (Figure 2(a)); OR $=0.498,95 \% \mathrm{CI}=0.296-0.838$ for TT versus CC (Figure 2(b)); OR $=0.573,95 \% \mathrm{CI}=0.348-$ 0.943 for TT + CC versus CC (Figure 2(d)); OR =0.746, $95 \% \mathrm{CI}=0.575-0.967$ for TT versus TT + TC (Figure $2(\mathrm{e})))$. Statistically significant association was also observed between rs 1799983 and POAG $(\mathrm{OR}=0.753,95 \% \mathrm{CI}=0.568-0.997$ for GG versus AA (Figure 3(b)); OR $=0.745,95 \% \mathrm{CI}=0.559-$ 0.993 for GA versus AA (Figure 3(c)); OR $=0.752,95 \% \mathrm{CI}=$ 0.576-0.983 for GG + GA versus AA (Figure 3(d))).

To further explore the association, stratified analysis was performed based on ethnicity (Caucasians and Asians) and sex. For rs2070744, the results showed that the association between rs2070744 and POAG was significant in Caucasians 


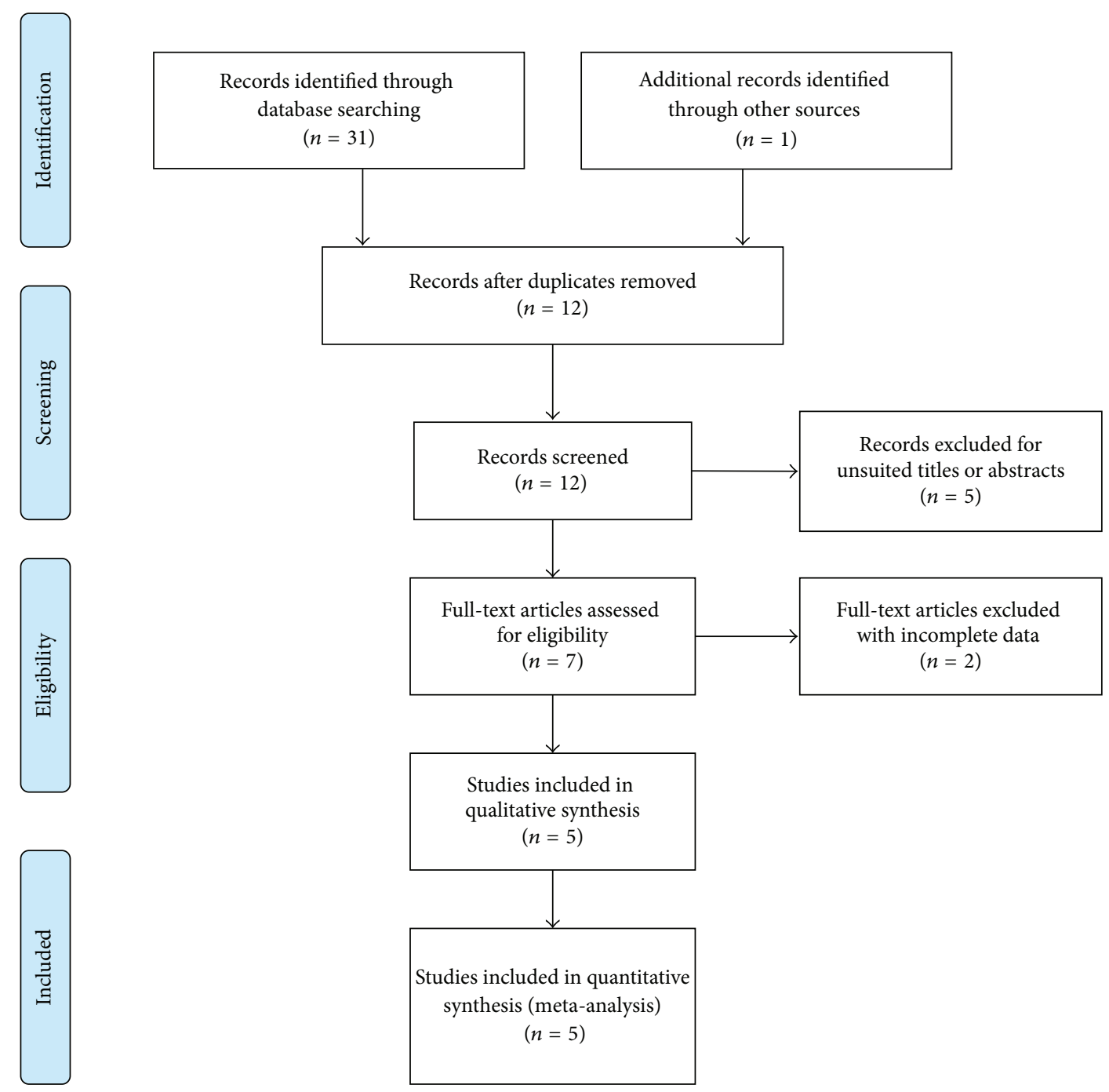

FIGURE 1: PRISMA flow diagram of studies included in the meta-analysis.

TABLE 1: Principle characteristics of the studies included in the meta-analysis for association between eNOS rs2070744 and POAG.

\begin{tabular}{lccccccccccccccccc}
\hline \multirow{2}{*}{ First author } & \multirow{2}{*}{ Cohorts } & \multirow{2}{*}{ Year } & \multirow{2}{*}{ Ethnicity } & \multirow{2}{*}{ Genotyping } & \multicolumn{4}{c}{ Case } & \multicolumn{4}{c}{ Control } \\
& & & & & & Size & GG & GA & AA & MAF & Size & GG & GA & AA & MAF & HWE $(p)$ \\
\hline Fan [16] & All & 2010 & Asians & NA & 397 & 319 & 72 & 6 & 0.11 & 201 & 157 & 43 & 1 & 0.11 & 0.44 \\
\hline \multirow{3}{*}{ Kang [17] } & All & 2011 & Caucasians & Taqman & 510 & 236 & 203 & 71 & 0.34 & 1444 & 682 & 598 & 164 & 0.32 & 0.28 \\
& Male & 2011 & Caucasians & Taqman & 147 & 72 & 60 & 15 & 0.31 & 425 & 203 & 170 & 52 & 0.32 & 0.06 \\
& Female & 2011 & Caucasians & Taqman & 363 & 164 & 143 & 56 & 0.35 & 1019 & 479 & 428 & 112 & 0.32 & 0.08 \\
\hline \multirow{3}{*}{ Magalhães da Silva [18] } & All & 2012 & Caucasians & Taqman & 89 & 55 & 27 & 7 & 0.23 & 124 & 72 & 46 & 6 & 0.23 & 0.28 \\
& Male & 2012 & Caucasians & Taqman & 28 & 20 & 7 & 1 & 0.16 & 63 & 35 & 24 & 4 & 0.25 & 0.70 \\
& Female & 2012 & Caucasians & Taqman & 61 & 35 & 22 & 4 & 0.25 & 61 & 37 & 23 & 1 & 0.20 & 0.97 \\
\hline \multirow{3}{*}{ Emam [19] } & All & 2014 & Caucasians & PCR-RFLP & 160 & 81 & 59 & 20 & 0.31 & 110 & 63 & 37 & 10 & 0.26 & 0.22 \\
& Male & 2014 & Caucasians & PCR-RFLP & 76 & 41 & 24 & 11 & 0.11 & 56 & 32 & 19 & 5 & 0.11 & 0.19 \\
& Female & 2014 & Caucasians & PCR-RFLP & 84 & 40 & 35 & 9 & 0.34 & 54 & 31 & 18 & 5 & 0.32 & 0.39 \\
\hline
\end{tabular}

NA: data not available; MAF: Minor Allele Frequency; HWE: Hardy-Weinberg equilibrium; PCR-RFLP: polymerase chain reaction-restriction fragment length polymorphism. 
TABLE 2: Principle characteristics of the studies included in the meta-analysis for association between eNOS rs1799983 and POAG.

\begin{tabular}{lccccccccccccccc}
\hline \multirow{2}{*}{ First author } & \multirow{2}{*}{ Cohorts } & \multirow{2}{*}{ Year } & \multirow{2}{*}{ Ethnicity } & \multirow{2}{*}{ Genotyping } & \multicolumn{4}{c}{ Case } & \multicolumn{4}{c}{ Control } \\
& & & & & & \multicolumn{3}{c}{ Control } \\
Lin [15] & All & 2005 & Asians & Taqman & 66 & 55 & 11 & 0 & 0.08 & 100 & 84 & 16 & 0 & 0.08 & 0.38 \\
\hline Fan [16] & All & 2010 & Asians & NA & 397 & 310 & 77 & 10 & 0.12 & 201 & 157 & 40 & 4 & 0.12 & 0.45 \\
\hline \multirow{3}{*}{ Kang [17] } & All & 2011 & Caucasians & Taqman & 518 & 202 & 232 & 84 & 0.39 & 1501 & 580 & 673 & 248 & 0.39 & 0.03 \\
& Male & 2011 & Caucasians & Taqman & 153 & 65 & 66 & 22 & 0.36 & 457 & 166 & 215 & 76 & 0.40 & 0.65 \\
& Female & 2011 & Caucasians & Taqman & 365 & 137 & 166 & 62 & 0.40 & 1044 & 414 & 458 & 172 & 0.38 & 0.02 \\
\hline \multirow{3}{*}{ Magalhães da Silva [18] } & All & 2012 & Caucasians & Taqman & 89 & 42 & 39 & 8 & 0.31 & 123 & 74 & 38 & 11 & 0.24 & 0.07 \\
& Male & 2012 & Caucasians & Taqman & 28 & 16 & 10 & 2 & 0.25 & 61 & 35 & 22 & 4 & 0.25 & 0.83 \\
& Female & 2012 & Caucasians & Taqman & 61 & 26 & 28 & 7 & 0.34 & 62 & 39 & 20 & 3 & 0.21 & 0.83 \\
\hline \multirow{3}{*}{ Emam [19] } & All & 2014 & Caucasians & PCR-RFLP & 160 & 63 & 59 & 38 & 0.42 & 110 & 60 & 38 & 12 & 0.28 & 0.12 \\
& Male & 2014 & Caucasians & PCR-RFLP & 76 & 32 & 26 & 18 & 0.08 & 56 & 30 & 19 & 7 & 0.08 & 0.17 \\
& Female & 2014 & Caucasians & PCR-RFLP & 84 & 31 & 33 & 20 & 0.12 & 54 & 30 & 19 & 5 & 0.12 & 0.44 \\
\hline
\end{tabular}

NA: data not available; MAF: Minor Allele Frequency; HWE: Hardy-Weinberg equilibrium; PCR-RFLP: polymerase chain reaction-restriction fragment length polymorphism.

TABLE 3: Summary risk estimates for association between eNOS rs2070744 and POAG.

\begin{tabular}{|c|c|c|c|c|c|c|c|c|c|}
\hline & Comparisons & Studies $(n)$ & Model & $\begin{array}{c}\text { Pooled estimate } \\
\text { OR (95\% CI) }\end{array}$ & $p_{Z}$ & $\begin{array}{l}\text { Heterogeneity } \\
\qquad I^{2}(\%)\end{array}$ & $p_{Q}$ & $\begin{array}{l}\text { Egger's } \\
\text { test }(p)\end{array}$ & $\begin{array}{l}\text { Begg's } \\
\text { test }(p)\end{array}$ \\
\hline \multirow{5}{*}{ Overall } & T versus $C$ & 4 & $\mathrm{~F}$ & $0.736(0.594-0.912)$ & 0.005 & 44.8 & 0.143 & 0.724 & 0.734 \\
\hline & TT versus CC & 4 & $\mathrm{~F}$ & $0.498(0.296-0.838)$ & 0.009 & 21.6 & 0.279 & 0.236 & 1.000 \\
\hline & TC versus CC & 4 & $\mathrm{~F}$ & $0.725(0.425-1.239)$ & 0.240 & 25.0 & 0.264 & 0.561 & 1.000 \\
\hline & $\mathrm{TT}+\mathrm{TC}$ versus $\mathrm{CC}$ & 4 & $\mathrm{~F}$ & $0.573(0.348-0.943)$ & 0.029 & 25.1 & 0.263 & 0.379 & 1.000 \\
\hline & $\mathrm{TT}$ versus $\mathrm{TC}+\mathrm{CC}$ & 4 & $\mathrm{~F}$ & $0.746(0.575-0.967)$ & 0.027 & 34.6 & 0.205 & 0.873 & 1.000 \\
\hline \multirow{5}{*}{ Female } & T versus $C$ & 2 & $\mathrm{~F}$ & $0.490(0.333-0.721)$ & 0.000 & 0.0 & 0.887 & & \\
\hline & TT versus CC & 2 & $\mathrm{~F}$ & $0.268(0.112-0.642)$ & 0.003 & 0.0 & 0.913 & & \\
\hline & TC versus CC & 2 & $\mathrm{~F}$ & $0.489(0.200-1.196)$ & 0.117 & 0.0 & 0.732 & & \\
\hline & $\mathrm{TT}+\mathrm{TC}$ versus $\mathrm{CC}$ & 2 & $\mathrm{~F}$ & $0.328(0.144-0.749)$ & 0.008 & 0.0 & 0.764 & & \\
\hline & TT versus $\mathrm{TC}+\mathrm{CC}$ & 2 & $\mathrm{~F}$ & $0.423(0.260-0.689)$ & 0.001 & 0.0 & 0.896 & & \\
\hline \multirow{5}{*}{ Male } & $\mathrm{T}$ versus $\mathrm{C}$ & 2 & $\mathrm{~F}$ & $0.711(0.467-1.081)$ & 0.111 & 8.4 & 0.296 & & \\
\hline & TT versus CC & 2 & $\mathrm{~F}$ & $0.496(0.211-1.175)$ & 0.111 & 0.0 & 0.452 & & \\
\hline & TC versus CC & 2 & $\mathrm{~F}$ & $0.604(0.244-1.496)$ & 0.276 & 0.0 & 0.623 & & \\
\hline & $\mathrm{TT}+\mathrm{TC}$ versus $\mathrm{CC}$ & 2 & $\mathrm{~F}$ & $0.513(0.230-1.144)$ & 0.103 & 0.0 & 0.476 & & \\
\hline & $\mathrm{TT}$ versus $\mathrm{TC}+\mathrm{CC}$ & 2 & $\mathrm{~F}$ & $0.688(0.406-1.165)$ & 0.164 & 0.0 & 0.328 & & \\
\hline \multirow{5}{*}{ Asians } & T versus $C$ & 2 & $\mathrm{~F}$ & $0.971(0.695-1.358)$ & 0.864 & 0.0 & 0.967 & & \\
\hline & TT versus CC & 2 & $\mathrm{~F}$ & $0.790(0.244-2.558)$ & 0.694 & - & - & & \\
\hline & TC versus CC & 2 & $\mathrm{~F}$ & $0.770(0.227-2.610)$ & 0.675 & - & - & & \\
\hline & $\mathrm{TT}+\mathrm{TC}$ versus $\mathrm{CC}$ & 2 & $\mathrm{~F}$ & $0.786(0.243-2.537)$ & 0.687 & - & - & & \\
\hline & TT versus $\mathrm{TC}+\mathrm{CC}$ & 2 & $\mathrm{~F}$ & $0.990(0.684-1.431)$ & 0.955 & 0.0 & 0.921 & & \\
\hline \multirow{5}{*}{ Caucasians } & T versus $\mathrm{C}$ & 2 & $\mathrm{~F}$ & $0.607(0.460-0.803)$ & 0.001 & 3.2 & 0.310 & & \\
\hline & TT versus CC & 2 & $\mathrm{~F}$ & $0.444(0.249-0.791)$ & 0.006 & 46.1 & 0.173 & & \\
\hline & TC versus CC & 2 & $\mathrm{R}$ & $0.715(0.394-1.296)$ & 0.269 & 62.4 & 0.103 & & \\
\hline & $\mathrm{TT}+\mathrm{TC}$ versus $\mathrm{CC}$ & 2 & $\mathrm{R}$ & $0.534(0.308-0.925)$ & 0.025 & 57.7 & 0.124 & & \\
\hline & $\mathrm{TT}$ versus $\mathrm{TC}+\mathrm{CC}$ & 2 & $\mathrm{~F}$ & $0.563(0.390-0.812)$ & 0.002 & 0.0 & 0.813 & & \\
\hline
\end{tabular}

OR: odds ratio; CI: confidence interval; $p_{Z}$ : $p$ value for $Z$ test; $p_{\mathrm{Q}}$ : $p$ value for $Q$-test; F: fixed-effects mode; R: random-effects model; -: data not available. 
TABLE 4: Summary risk estimates for association between eNOS rs1799983 and POAG.

\begin{tabular}{|c|c|c|c|c|c|c|c|c|c|}
\hline & Comparisons & Studies $(n)$ & Model & $\begin{array}{c}\text { Pooled estimate } \\
\text { OR }(95 \% \text { CI })\end{array}$ & $p_{Z}$ & $\begin{array}{l}\text { Heterogeneity } \\
I^{2}(\%)\end{array}$ & $p_{\mathrm{Q}}$ & $\begin{array}{l}\text { Egger's } \\
\text { test }(p)\end{array}$ & $\begin{array}{l}\text { Begg's } \\
\text { test }(p)\end{array}$ \\
\hline \multirow{5}{*}{ Overall } & G versus $A$ & 4 & $\mathrm{~F}$ & $0.928(0.817-1.053)$ & 0.247 & 0.0 & 0.694 & 0.851 & 0.734 \\
\hline & GG versus AA & 4 & $\mathrm{~F}$ & $0.753(0.568-0.997)$ & 0.048 & 0.0 & 0.831 & 0.039 & 0.308 \\
\hline & GA versus AA & 4 & $\mathrm{~F}$ & $0.745(0.559-0.993)$ & 0.045 & 0.0 & 0.720 & 0.149 & 0.089 \\
\hline & $\mathrm{GG}+\mathrm{GA}$ versus $\mathrm{AA}$ & 4 & $\mathrm{~F}$ & $0.752(0.576-0.983)$ & 0.037 & 0.0 & 0.824 & 0.033 & 0.089 \\
\hline & GG versus $\mathrm{GA}+\mathrm{AA}$ & 4 & $\mathrm{~F}$ & $0.979(0.832-1.153)$ & 0.803 & 0.0 & 0.584 & 0.832 & 1.000 \\
\hline \multirow{5}{*}{ Female } & G versus $A$ & 3 & $\mathrm{~F}$ & $0.852(0.724-1.003)$ & 0.054 & 0.0 & 0.869 & & \\
\hline & GG versus AA & 3 & $\mathrm{~F}$ & $0.665(0.471-0.938)$ & 0.020 & 0.0 & 0.651 & & \\
\hline & GA versus AA & 3 & $\mathrm{~F}$ & $0.674(0.474-0.958)$ & 0.028 & 0.0 & 0.505 & & \\
\hline & $G G+G A$ versus $A A$ & 3 & $\mathrm{~F}$ & $0.666(0.481-0.923)$ & 0.015 & 0.0 & 0.626 & & \\
\hline & GG versus $\mathrm{GA}+\mathrm{AA}$ & 3 & $\mathrm{~F}$ & $0.894(0.720-1.108)$ & 0.306 & 0.0 & 0.684 & & \\
\hline \multirow{5}{*}{ Male } & G versus $A$ & 3 & $\mathrm{~F}$ & $1.067(0.839-1.358)$ & 0.595 & 20.7 & 0.283 & & \\
\hline & GG versus AA & 3 & $\mathrm{~F}$ & $1.085(0.641-1.836)$ & 0.124 & 0.0 & 0.431 & & \\
\hline & GA versus AA & 3 & $\mathrm{~F}$ & $1.041(0.604-1.793)$ & 0.885 & 0.0 & 0.557 & & \\
\hline & $\mathrm{GG}+\mathrm{GA}$ versus $\mathrm{AA}$ & 3 & $\mathrm{~F}$ & $1.066(0.643-1.768)$ & 0.804 & 0.0 & 0.456 & & \\
\hline & GG versus GA + AA & 3 & $\mathrm{~F}$ & $1.088(0.798-1.485)$ & 0.593 & 0.0 & 0.378 & & \\
\hline \multirow{5}{*}{ Asians } & G versus $A$ & 1 & - & $1.065(0.726-1.564)$ & 0.746 & - & - & & \\
\hline & GG versus AA & 1 & - & $0.339(0.040-2.837)$ & 0.682 & - & - & & \\
\hline & GA versus AA & 1 & - & $0.279(0.032-2.397)$ & 0.245 & - & - & & \\
\hline & $\mathrm{GG}+\mathrm{GA}$ versus $\mathrm{AA}$ & 1 & - & $0.326(0.039-2.725)$ & 0.301 & - & - & & \\
\hline & GG versus $\mathrm{GA}+\mathrm{AA}$ & 1 & - & $1.146(0.756-1.737)$ & 0.520 & - & - & & \\
\hline \multirow{5}{*}{ Caucasians } & G versus $A$ & 3 & $\mathrm{~F}$ & $0.912(0.797-1.043)$ & 0.180 & 0.0 & 0.641 & & \\
\hline & GG versus AA & 3 & $\mathrm{~F}$ & $0.768(0.578-1.021)$ & 0.069 & 0.0 & 0.855 & & \\
\hline & GA versus AA & 3 & $\mathrm{~F}$ & $0.765(0.572-1.023)$ & 0.071 & 0.0 & 0.776 & & \\
\hline & GG + GA versus AA & 3 & $\mathrm{~F}$ & $0.767(0.585-1.006)$ & 0.055 & 0.0 & 0.866 & & \\
\hline & GG versus GA + AA & 3 & $\mathrm{~F}$ & $0.952(0.798-1.137)$ & 0.803 & 0.0 & 0.584 & & \\
\hline
\end{tabular}

OR: odds ratio; CI: confidence interval; $p_{Z}$ : $p$ value for $Z$ test; $p_{Q}$ : $p$ value for $Q$-test; F: fixed-effects mode; -: data not available.

$(\mathrm{OR}=0.607,95 \% \mathrm{CI}=0.460-0.803$ for $\mathrm{T}$-allele versus $\mathrm{C}$ allele; $\mathrm{OR}=0.444,95 \% \mathrm{CI}=0.249-0.791$ for $\mathrm{TT}$ versus CC; OR = $0.534,95 \% \mathrm{CI}=0.308-0.925$ for $\mathrm{TT}+\mathrm{CC}$ versus CC; OR = $0.563,95 \% \mathrm{CI}=0.390-0.812$ for TT versus TT + TC) but not in Asians (Table 3). Stratified analysis based on sex supported a link only in female group $(\mathrm{OR}=0.490,95 \% \mathrm{CI}=0.333-$ 0.721 for T-allele versus C allele; $\mathrm{OR}=0.268,95 \% \mathrm{CI}=0.112-$ 0.642 for TT versus CC; $\mathrm{OR}=0.328,95 \% \mathrm{CI}=0.144-0.749$ for TT + CC versus CC; OR $=0.423,95 \% \mathrm{CI}=0.260-0.689$ for TT versus TT + TC (Table 3)). For rs1799983, the results revealed no evidence of the association in neither Caucasians nor Asians (Table 4). As expected, statistical association was found in female subgroup $(\mathrm{OR}=0.665,95 \% \mathrm{CI}=0.471-0.938$ for $\mathrm{GG}$ versus $\mathrm{AA}$; OR $=0.674,95 \% \mathrm{CI}=0.474-0.958$ for $\mathrm{GA}$ versus $\mathrm{AA}$; $\mathrm{OR}=0.666,95 \% \mathrm{CI}=0.481-0.923$ for $\mathrm{GG}+\mathrm{GA}$ versus AA). Consistently, we still found no relationship in the male subgroup (Table 4).

3.3. Publication Bias. Publication bias was quantitatively assessed by Begg's tests and Egger's tests. In the overall analysis, there was no evidence of publication bias detected for rs2070744 (Table 3). With regard to rs1799983, Egger's regression test suggested a weak indication of publication bias, whereas Begg's rank correlation test did not identify evidence of substantial publication bias (Table 4).

\section{Discussion}

We reviewed a broad selection of publications found in electronic databases and performed a meta-analysis, in an attempt to identify the effects of polymorphisms of the eNOS gene on the pathogenesis of POAG. Five eligible studies were involved and available data in this regard were conflicting [15-19]. After the results were pooled, the main finding of this study is that TT genotype and/or T-allele in rs2070744, as well as GG genotype and/or G-allele in rs1799983, could protect individuals from POAG risk. Stratified analysis based on ethnicity showed that the association of rs2070744 with POAG remained only in Caucasians, while no association between rs1799983 and POAG was found in either Caucasians or Asians. To further explore the association, we performed subgroup analysis by sex. The results indicated that TT genotype and/or T-allele in rs2070744 and GG genotype and/or G-allele in rs1799983 were favorable factors for POAG in female group, but not in male group. 


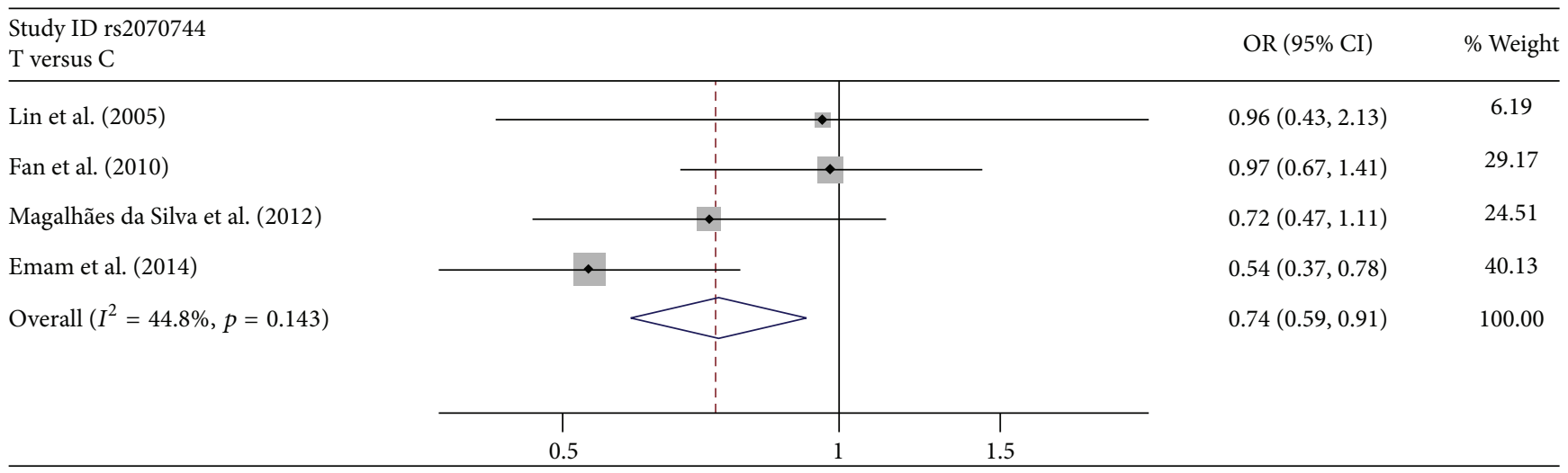

(a)

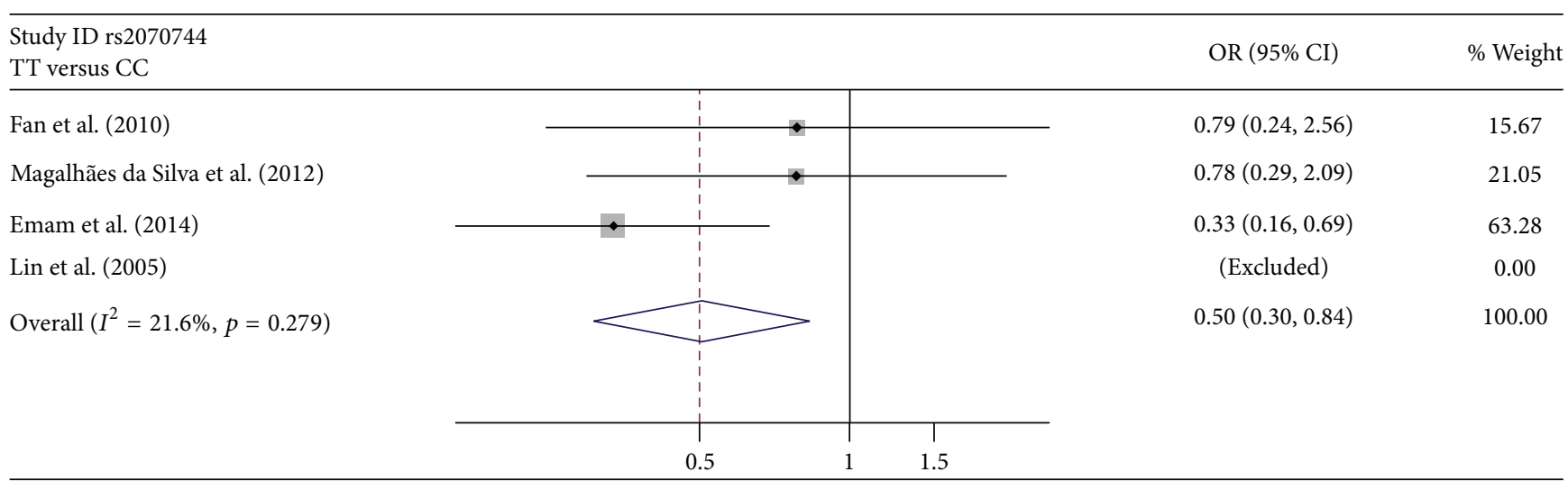

(b)

Study ID rs2070744

TC versus CC

OR (95\% CI)

$\%$ Weight

Fan et al. (2010)

Magalhães da Silva et al. (2012)

Emam et al. (2014)

Lin et al. (2005)

Overall $\left(I^{2}=25.0 \%, p=0.264\right)$

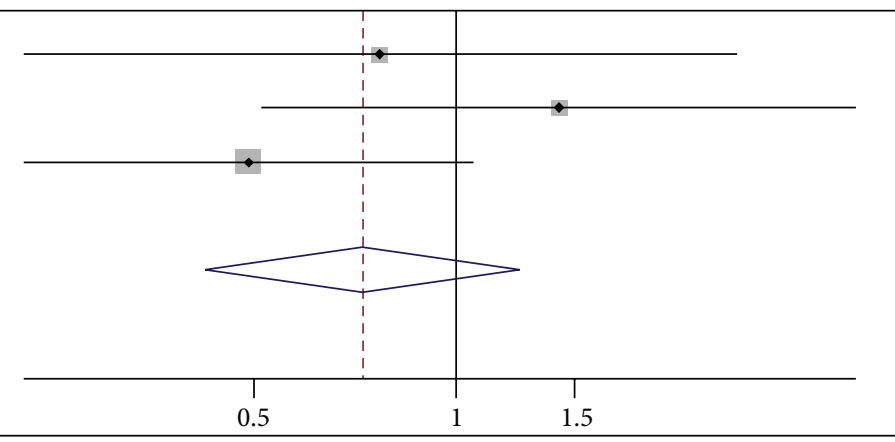

$\begin{array}{cc}0.77(0.23,2.61) & 19.03 \\ 1.41(0.51,3.89) & 19.74 \\ 0.49(0.23,1.06) & 61.23 \\ \text { (Excluded) } & 0.00\end{array}$

$0.73(0.42,1.24) \quad 100.00$

(c)

Study ID rs2070744

TT+TC versus CC

OR $(95 \% \mathrm{CI})$

$\%$ Weight

Fan et al. (2010)

Magalhães da Silva et al. (2012)

Emam et al. (2014)

Lin et al. (2005)

Overall $\left(I^{2}=25.1 \%, p=0.263\right)$

\begin{tabular}{r|ccc} 
\\
\hline
\end{tabular}

(d)

FIgURE 2: Continued. 


\begin{tabular}{ll|l}
\hline Study ID rs2070744 \\
TT versus TC+CC \\
\hline Lin et al. (2005) \\
Fan et al. (2010) \\
Magalhães da Silva et al. (2012) \\
Emam et al. (2014) \\
Overall $\left(I^{2}=34.6 \%, p=0.205\right)$
\end{tabular}

(e)

FIGURE 2: Forest plots of the association of rs2070744 with POAG. Every study was represented by a square whose size was proportional to the weight of the study. Diamond indicated summary odds ratios (ORs) with its corresponding 95\% confidence interval (95\% CI). (a) Forest plot for rs2070744 and POAG risk in the genetic model of T-allele versus C allele. (b) Forest plot for rs2070744 and POAG risk in the genetic model of TT versus CC. (c) Forest plot for rs2070744 and POAG risk in the genetic model of TC versus CC. (d) Forest plot for rs2070744 and POAG risk in the genetic model of TT + TC versus CC. (e) Forest plot for rs2070744 and POAG risk in the genetic model of TT versus TC + CC.

Generated by eNOS via the conversion of L-arginine to L-citrulline, $\mathrm{NO}$ acts as a pivotal vasodilator mediator liberated from endothelial cells of ocular blood vessels. There is evidence that constant formation of NO by eNOS provides the maintenance of a basal vasodilator tone in the optic nerve head of humans and experimental animals [26-30], which is a precondition of sufficient blood supply to this tissue. Earlier studies suggested that vascular dysregulation played an important role in the etiology of glaucoma [31, 32]. In accordance with this, Polak et al. observed the perfusion of the optic nerve head during NOS inhibition and found differences in ocular blood flow response between patients with POAG and controls, indicating an abnormal NO system and NOS activity in POAG patients [33]. Further, it was reported that the increased presence of eNOS in vascular endothelia may be neuroprotective by causing vasodilatation and increased blood flow in the glaucomatous tissue [34]. Besides, the activity of NOS in trabecular meshwork was observed in patients with POAG [35]. Based on these evidences, it is reasonable to assume that the polymorphisms of eNOS are associated with the pathogenesis of POAG.

Rs2070744 and rs1799983 are the most important identified functional polymorphisms of the eNOS. The polymorphism of the promoter region of eNOS rs2070744 has been considered to be related to nonarteritic anterior ischemic optic neuropathy (NAION), coronary spasm, myocardial infarction, and coronary artery disease [36-39]. This polymorphism reduces the transcription rate of the eNOS gene and then lowers eNOS mRNA and serum nitrite/nitrate levels $[40,41]$. As for eNOS rs1799983, the polymorphism has been associated with ischemic shock, coronary spasm, coronary artery disease, myocardial infarction, and NAION [38, 39, 42-44]. As this polymorphism is located in a coding region, it might be in relation to altered eNOS function and functional changes of the endothelium $[45,46]$. Several investigations to date were conducted to explore the links between these two polymorphisms and POAG but achieved inconsistent conclusions. Therefore, the present meta-analysis was performed to determine whether or not these two polymorphisms could predict susceptibility to POAG.

In our study, we observed associations between eNOS gene variants and POAG, particularly among the women, revealing some sex-related facts in pathogenesis. Several lines of evidence suggest the sexually dimorphic effects of eNOS. In a series of animal studies, the expression levels of eNOS exhibited sex disparity [47] and displayed different degrees of inhibition under the sex-dependent miR-222 regulation [48]. In a human study of 373 glaucoma cases and 1082 controls, Kang et al. found that eNOS SNPs showed significant interactions with current postmenopausal hormone use in relation to high tension POAG [49]. These findings are in line with our results. Although the basis of molecular mechanisms is not clear, we believe that there are several factors that may influence this discrepancy. Concerning biological factors, circulating estrogen may act directly on eNOS through nongenomic effects, resulting in rapid dilatation of blood vessels $[50,51]$. One recent study also indicates that estrogen induces NO production via NOS activation in endothelial cells [52]. Furthermore, women in most part of the world are more likely to adopt healthy lifestyle [53-56]. For example, cigarette smoking is proved to contribute to endothelial dysfunction through the uncoupling of the eNOS-mediated synthesis of $\mathrm{NO}[57,58]$ and a series of studies indicate that women obtained lower tobacco consumption than their male fellows [59-61].

For our study, we have put considerable efforts and attempted to minimize every bias and gain stable and reliable results; however, there are still some limitations. Firstly, studies involved in the present meta-analysis were limited to published full-text articles in English. We failed to track the unpublished articles or ones published in other languages to obtain data for analysis, causing an influence on 


\begin{tabular}{l} 
Study ID rs1799983 \\
G versus A \\
\hline Fan et al. (2010) \\
Kang et al. (2011) \\
Magalhães da Silva et al. (2012) \\
Emam et al. (2014) \\
Overall $\left(I^{2}=0.0 \%, p=0.694\right)$ \\
\hline
\end{tabular}

(a)

\begin{tabular}{l} 
Study ID rs1799983 \\
GG versus AA \\
\hline Fan et al. (2010) \\
Kang et al. (2011) \\
Magalhães da Silva et al. (2012) \\
Emam et al. (2014)
\end{tabular}

(b)

Study ID rs1799983

GA versus AA

Fan et al. (2010)

Kang et al. (2011)

Magalhães da Silva et al. (2012)

Emam et al. (2014)

Overall $\left(I^{2}=0.0 \%, p=0.720\right)$

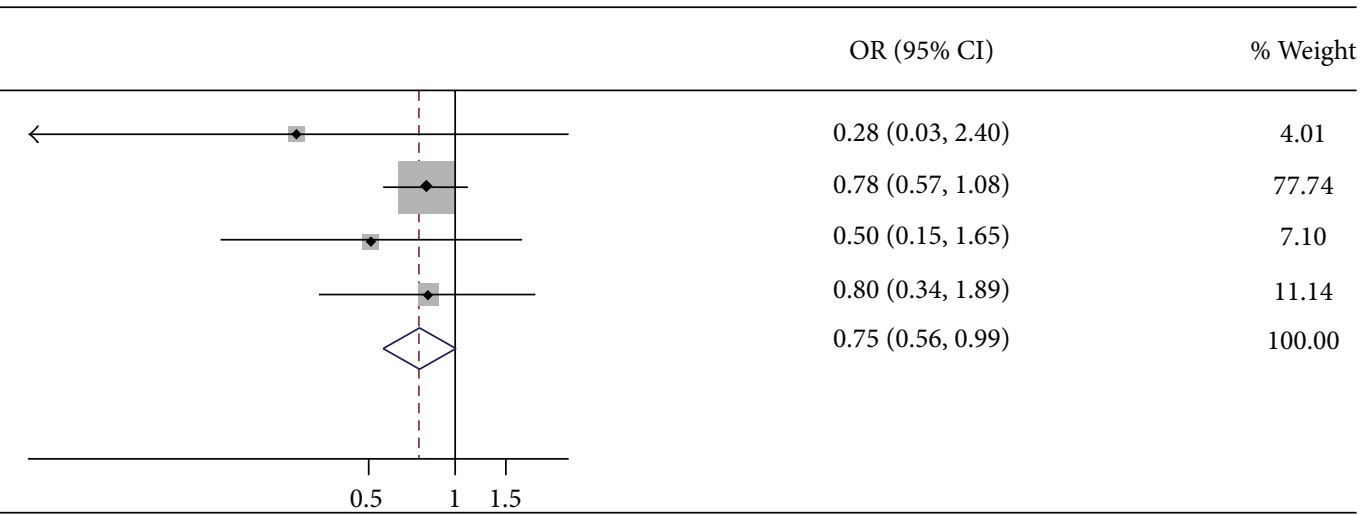

(c)

Study ID rs1799983

GG+GA versus AA

Fan et al. (2010)

Kang et al. (2011)

Magalhães da Silva et al. (2012)

Emam et al. (2014)

Overall $\left(I^{2}=0.0 \%, p=0.824\right)$

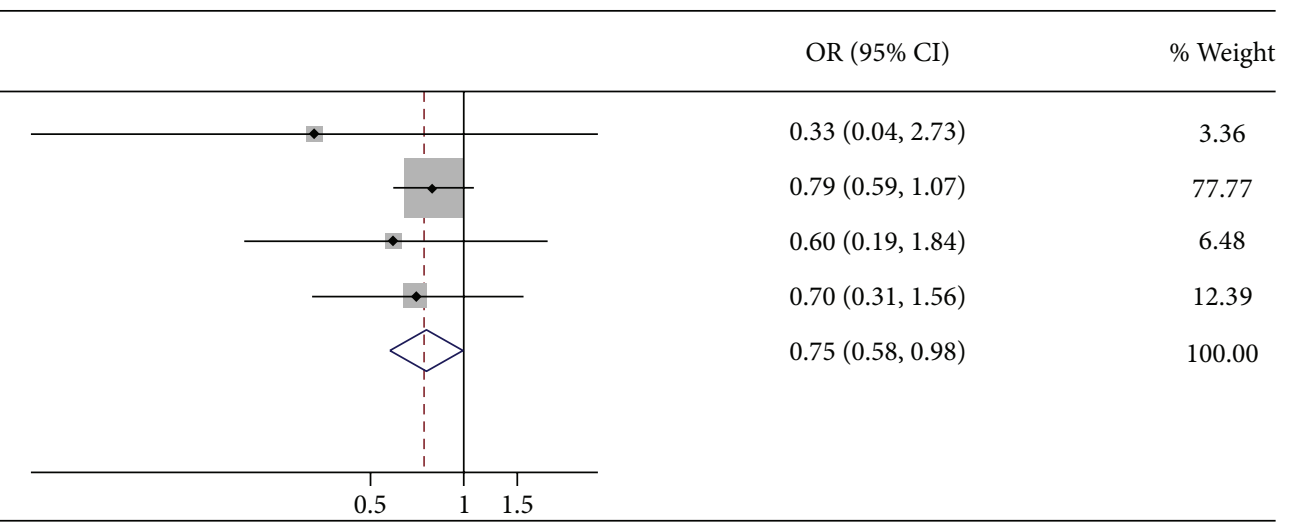

(d)

FIgure 3: Continued. 


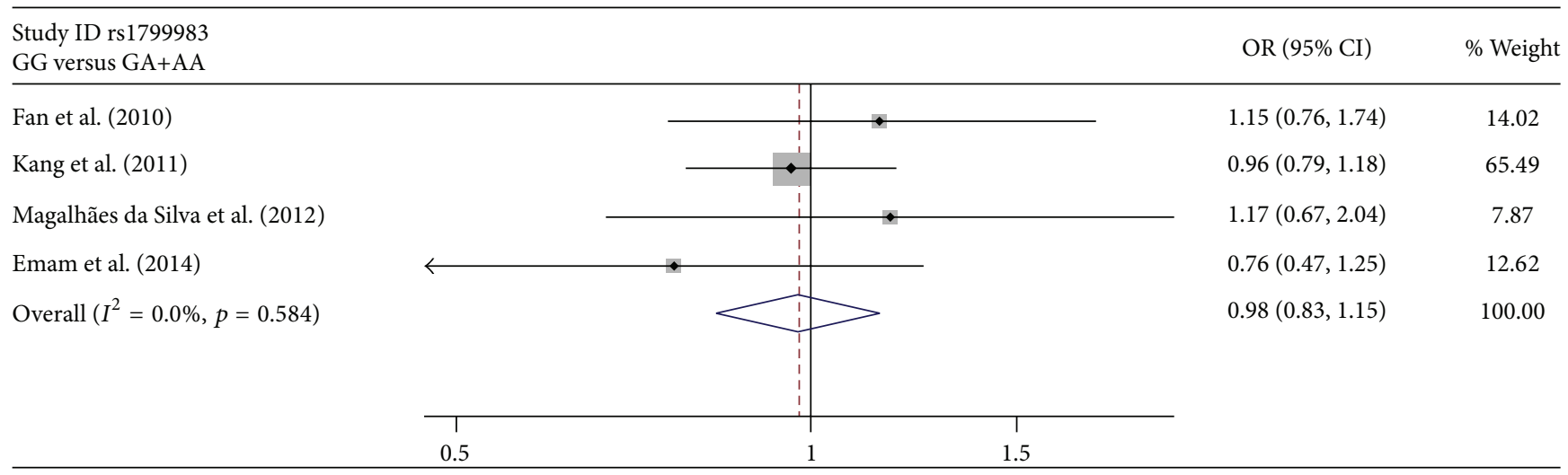

(e)

FIGURE 3: Forest plots of the association of rs1799983 with POAG. Every study was represented by a square whose size was proportional to the weight of the study. Diamond indicated summary odds ratios (ORs) with its corresponding 95\% confidence interval (95\% CI). (a) Forest plot for rs1799983 and POAG risk in the genetic model of G-allele versus A allele. (b) Forest plot for rs1799983 and POAG risk in the genetic model of GG versus AA. (c) Forest plot for rs1799983 and POAG risk in the genetic model of GA versus AA. (d) Forest plot for rs1799983 and POAG risk in the genetic model of GG + GA versus AA. (e) Forest plot for rs1799983 and POAG risk in the genetic model of GG versus $\mathrm{GA}+\mathrm{AA}$.

the completeness of the data. Secondly, although we collected and reviewed all the relevant studies, only five eligible ones were included for analysis and the sample size of the individual studies was not sufficiently large, which could increase the likelihood of type I and type II errors. As for rs2070744, we excluded one study with significant HWE deviation, further decreasing the overall sample size of our study. Therefore our results should be interpreted with caution until these findings can be replicated in other large datasets. Stratified analysis of ethnicity and sex also encountered the similar problem due to the lack of detailed data. Despite all of these limitations, we believe our study would be beneficial to a better understanding of the association between eNOS polymorphisms and POAG. Moreover, our analysis has also revealed the limitations in the current POAG genetic studies. Hence, large-scale and well-designed studies are warranted in the future. As stated, glaucoma was estimated to disproportionally affect people in Africa and thus more research needs to be conducted in the African population. Finally, since POAG is a multifactorial disease and the roles of several genes in the pathogenesis of POAG have been established, further investigations should be performed in this direction. It is possible that specific gene-gene and gene-environment interactions may alter those associations between gene polymorphisms and POAG. We expect that as more studies become available, a more accurate estimation of the relationship of eNOS with POAG will be obtained.

In summary, the current meta-analysis suggests that TT genotype and/or T-allele in rs2070744, as well as GG genotype and/or G-allele in rs1799983, was associated with decreased risk for POAG overall and in female group. To better understand the role of genetic factors in the physiopathology of this condition, further studies are needed in large, standardized, and ethnically diverse populations.

\section{Competing Interests}

The authors declare that they have no competing interests.

\section{Authors' Contributions}

Yang Xiang and Yi Dong contributed equally to this study.

\section{Acknowledgments}

The authors thank Qing Liu and Liangyu Guo from Tianjin Eye Hospital Library for helpful comments. And this research was supported by the National Natural Science Foundation of China (Grant no. 81270984).

\section{References}

[1] H. A. Quigley, "Number of people with glaucoma worldwide," The British Journal of Ophthalmology, vol. 80, no. 5, pp. 389-393, 1996.

[2] Y.-C. Tham, X. Li, T. Y. Wong, H. A. Quigley, T. Aung, and C.Y. Cheng, "Global prevalence of glaucoma and projections of glaucoma burden through 2040: a systematic review and metaanalysis," Ophthalmology, vol. 121, no. 11, pp. 2081-2090, 2014.

[3] Y. H. Kwom, J. H. Fingprt, M. H. Kuehn, and W. L. M. Alward, "Primary open-angle glaucoma," The New England Journal of Medicine, vol. 360, no. 11, pp. 1113-1124, 2009.

[4] B.-J. Fan, Y.-F. Leung, N. Wang et al., "Genetic and environmental risk factors for primary open-angle glaucoma," Chinese Medical Journal, vol. 117, no. 5, pp. 706-710, 2004.

[5] K. S. Kooner, M. AlBdoor, B. J. Cho, and B. Adams-Huet, "Risk factors for progression to blindness in high tension primary open angle glaucoma: comparison of blind and nonblind subjects," Clinical Ophthalmology, vol. 2, no. 4, pp. 757-762, 2008 . 
[6] F. Ma, J. Dai, and X. Sun, "Progress in understanding the association between high myopia and primary open-angle glaucoma," Clinical and Experimental Ophthalmology, vol. 42, no. 2, pp. 190-197, 2014.

[7] N. Orzalesi, L. Rossetti, and S. Omboni, "Vascular risk factors in glaucoma: the results of a national survey," Graefe's Archive for Clinical and Experimental Ophthalmology, vol. 245, no. 6, pp. 795-802, 2007.

[8] W.-W. Su, S.-T. Cheng, W.-J. Ho, P.-K. Tsay, S.-C. Wu, and S. H. L. Chang, "Glaucoma is associated with peripheral vascular endothelial dysfunction," Ophthalmology, vol. 115, no. 7, pp. 1173-1178.e1, 2008.

[9] G. Lascaratos, D. F. Garway-Heath, C. E. Willoughby, K.-Y. Chau, and A. H. V. Schapira, "Mitochondrial dysfunction in glaucoma: understanding genetic influences," Mitochondrion, vol. 12, no. 2, pp. 202-212, 2012.

[10] R. T. Libby, D. B. Gould, M. G. Anderson, and S. W. M. John, "Complex genetics of glaucoma susceptibility," Annual Review of Genomics and Human Genetics, vol. 6, pp. 15-44, 2005.

[11] Y. Liu and R. R. Allingham, "Molecular genetics in glaucoma," Experimental Eye Research, vol. 93, no. 4, pp. 331-339, 2011.

[12] K. Bian and F. Murad, "What is next in nitric oxide research? From cardiovascular system to cancer biology," Nitric Oxide, vol. 43, pp. 3-7, 2014.

[13] F. Karantzoulis-Fegaras, H. Antoniou, S.-L. M. Lai et al., "Characterization of the human endothelial nitric-oxide synthase promoter," The Journal of Biological Chemistry, vol. 274, no. 5, pp. 3076-3093, 1999.

[14] N. Toda and M. Nakanishi-Toda, "Nitric oxide: ocular blood flow, glaucoma, and diabetic retinopathy," Progress in Retinal and Eye Research, vol. 26, no. 3, pp. 205-238, 2007.

[15] H.-J. Lin, C.-H. Tsai, F.-J. Tsai, W.-C. Chen, S.-W. Tsai, and S.-S. Fan, "Distribution of oxidation enzyme eNOS and myeloperoxidase in primary open angle glaucoma," Journal of Clinical Laboratory Analysis, vol. 19, no. 2, pp. 87-92, 2005.

[16] B. J. Fan, K. Liu, D. Y. Wang et al., "Association of polymorphisms of tumor necrosis factor and tumor protein p53 with primary open-angle glaucoma," Investigative Ophthalmology \& Visual Science, vol. 51, no. 8, pp. 4110-4116, 2010.

[17] J. H. Kang, J. L. Wiggs, B. A. Rosner, J. Haines, W. Abdrabou, and L. R. Pasquale, "Endothelial nitric oxide synthase gene variants and primary open-angle glaucoma: interactions with hypertension, alcohol intake, and cigarette smoking," Archives of Ophthalmology, vol. 129, no. 6, pp. 773-780, 2011.

[18] T. Magalhães da Silva, A. V. Rocha, R. Lacchini et al., "Association of polymorphisms of endothelial nitric oxide synthase (eNOS) gene with the risk of primary open angle glaucoma in a Brazilian population," Gene, vol. 502, no. 2, pp. 142-146, 2012.

[19] W. A. Emam, H. E. Zidan, B.-E. H. Abdulhalim, S. A. Dabour, M. A. Ghali, and A. T. Kamal, "Endothelial nitric oxide synthase polymorphisms and susceptibility to high-tension primary open-angle glaucoma in an Egyptian cohort," Molecular Vision, vol. 20, pp. 804-811, 2014.

[20] Q. Liao, D.-H. Wang, and H.-J. Sun, "Association of genetic polymorphisms of eNOS with glaucoma," Molecular Vision, vol. 17, pp. 153-158, 2011.

[21] J. Attia, A. Thakkinstian, and C. D’Este, "Meta-analyses of molecular association studies: methodologic lessons for genetic epidemiology," Journal of Clinical Epidemiology, vol. 56, no. 4, pp. 297-303, 2003.
[22] R. DerSimonian, "Meta-analysis in the design and monitoring of clinical trials," Statistics in Medicine, vol. 15, no. 12, pp. 12371252, 1996.

[23] N. Mantel and W. Haenszel, "Statistical aspects of the analysis of data from retrospective studies of disease," Journal of the National Cancer Institute, vol. 22, no. 4, pp. 719-748, 1959.

[24] J. Copas and J. Q. Shi, "Meta-analysis, funnel plots and sensitivity analysis," Biostatistics, vol. 1, no. 3, pp. 247-262, 2000.

[25] R. M. Harbord, M. Egger, and J. A. C. Sterne, "A modified test for small-study effects in meta-analyses of controlled trials with binary endpoints," Statistics in Medicine, vol. 25, no. 20, pp. 3443-3457, 2006.

[26] A. Luksch, K. Polak, C. Beier et al., "Effects of systemic NO synthase inhibition on choroidal and optic nerve head blood flow in healthy subjects," Investigative Ophthalmology \& Visual Science, vol. 41, no. 10, pp. 3080-3084, 2000.

[27] I. O. Haefliger, J. Flammer, and T. F. Luscher, "Heterogeneity of endothelium-dependent regulation in ophthalmic and ciliary arteries," Investigative Ophthalmology \& Visual Science, vol. 34, no. 5, pp. 1722-1730, 1993.

[28] G. Garhöfer, H. Resch, S. Lung, G. Weigert, and L. Schmetterer, "Intravenous administration of L-arginine increases retinal and choroidal blood flow," American Journal of Ophthalmology, vol. 140, no. 1, pp. 69-76, 2005.

[29] M. C. Koss, "Role of nitric oxide in maintenance of basal anterior choroidal blood flow in rats," Investigative Ophthalmology \& Visual Science, vol. 39, no. 3, pp. 559-564, 1998.

[30] M. C. Koss, "Effects of inhibition of nitric oxide synthase on basal anterior segment ocular blood flows and on potential autoregulatory mechanisms," Journal of Ocular Pharmacology and Therapeutics, vol. 17, no. 4, pp. 319-329, 2001.

[31] S. S. Hayreh, M. B. Zimmerman, P. Podhajsky, and W. L. M. Alward, "Nocturnal arterial hypotension and its role in optic nerve head and ocular ischemic disorders," American Journal of Ophthalmology, vol. 117, no. 5, pp. 603-624, 1994.

[32] J. F. J. Logan, U. Chakravarthy, A. E. Hughes, C. C. Patterson, J. A. Jackson, and S. J. A. Rankin, "Evidence for association of endothelial nitric oxide synthase gene in subjects with glaucoma and a history of migraine," Investigative Ophthalmology \& Visual Science, vol. 46, no. 9, pp. 3221-3226, 2005.

[33] K. Polak, A. Luksch, F. Berisha, G. Fuchsjaeger-Mayrl, S. Dallinger, and L. Schmetterer, "Altered nitric oxide system in patients with open-angle glaucoma," Archives of Ophthalmology, vol. 125, no. 4, pp. 494-498, 2007.

[34] A. H. Neufeld, M. R. Hemandez, and M. Gonzalez, "Nitric oxide synthase in the human glaucomatous optic nerve head," Archives of Ophthalmology, vol. 115, no. 4, pp. 497-503, 1997.

[35] C. Stefan, D. M. Dumitrica, and C. Ardeleanu, "The future started: nitric oxide in glaucoma," Oftalmologia, vol. 51, no. 4, pp. 89-94, 2007.

[36] M. Nakayama, H. Yasue, M. Yoshimura et al., " $T^{-786} \rightarrow C$ mutation in the $5^{\prime}$-flanking region of the endothelial nitric oxide synthase gene is associated with myocardial infarction, especially without coronary organic stenosis," The American Journal of Cardiology, vol. 86, no. 6, pp. 628-634, 2000.

[37] M. Nakayama, H. Yasue, M. Yoshimura et al., " $\mathrm{T}^{-786} \rightarrow \mathrm{C}$ mutation in the $5^{\prime}$-flanking region of the endothelial nitric oxide synthase gene is associated with coronary spasm," Circulation, vol. 99, no. 22, pp. 2864-2870, 1999.

[38] T. Sakai, K. Shikishima, M. Matsushima, and K. Kitahara, "Endothelial nitric oxide synthase gene polymorphisms in nonarteritic anterior ischemic optic neuropathy," Graefe's Archive for 
Clinical and Experimental Ophthalmology, vol. 245, no. 2, pp. 288-292, 2007.

[39] M. G. Colombo, U. Paradossi, M. G. Andreassi et al., "Endothelial nitric oxide synthase gene polymorphisms and risk of coronary artery disease," Clinical Chemistry, vol. 49, no. 3, pp. 389-395, 2003.

[40] Y. Miyamoto, Y. Saito, M. Nakayama et al., "Replication protein A1 reduces transcription of the endothelial nitric oxide synthase gene containing a $-786 \mathrm{~T} \rightarrow \mathrm{C}$ mutation associated with coronary spastic angina," Human Molecular Genetics, vol. 9, no. 18, pp. 2629-2637, 2000.

[41] A. A. Doshi, M. T. Ziolo, H. Wang, E. Burke, A. Lesinski, and P. Binkley, "A promoter polymorphism of the endothelial nitric oxide synthase gene is associated with reduced mRNA and protein expression in failing human myocardium," Journal of Cardiac Failure, vol. 16, no. 4, pp. 314-319, 2010.

[42] K. Berger, F. Stögbauer, M. Stoll et al., "The glu298asp polymorphism in the nitric oxide synthase 3 gene is associated with the risk of ischemic stroke in two large independent case-control studies," Human Genetics, vol. 121, no. 2, pp. 169-178, 2007.

[43] K. Hibi, T. Ishigami, K. Tamura et al., "Endothelial nitric oxide synthase gene polymorphism and acute myocardial infarction," Hypertension, vol. 32, no. 3, pp. 521-526, 1998.

[44] M. Yoshimura, H. Yasue, M. Nakayama et al., "A missense Glu298Asp variant in the endothelial nitric oxide synthase gene is associated with coronary spasm in the Japanese," Human Genetics, vol. 103, no. 1, pp. 65-69, 1998.

[45] V. Godfrey, S.-L. Chan, A. Cassidy et al., "The functional consequence of the Glu298Asp polymorphism of the endothelial nitric oxide synthase gene in young healthy volunteers," Cardiovascular Drug Reviews, vol. 25, no. 3, pp. 280-288, 2007.

[46] S. K. Wattanapitayakul, M. J. Mihm, A. P. Young, and J. A. Bauer, "Therapeutic implications of human endothelial nitric oxide synthase gene polymorphism," Trends in Pharmacological Sciences, vol. 22, no. 7, pp. 361-368, 2001.

[47] H. R. Cross, E. Murphy, and C. Steenbergen, " $\mathrm{Ca}^{2+}$ loading and adrenergic stimulation reveal male/female differences in susceptibility to ischemia-reperfusion injury," American Journal of Physiology-Heart and Circulatory Physiology, vol. 283, no. 2, pp. H481-H489, 2002.

[48] A. M. Evangelista, A. M. Deschamps, D. Liu, N. Raghavachari, and E. Murphy, "miR-222 Contributes to sex-dimorphic cardiac eNOS expression via ets-1," Physiological Genomics, vol. 45, no. 12, pp. 493-498, 2013.

[49] J. H. Kang, J. L. Wiggs, B. A. Rosner et al., "Endothelial nitric oxide synthase gene variants and primary open-angle glaucoma: interactions with sex and postmenopausal hormone use," Investigative Ophthalmology \& Visual Science, vol. 51, no. 2, pp. 971-979, 2010.

[50] S. Yang, L. Bae, and L. Zhang, "Estrogen increases eNOS and $\mathrm{NO}_{x}$ release in human coronary artery endothelium," Journal of Cardiovascular Pharmacology, vol. 36, no. 2, pp. 242-247, 2000.

[51] K. Hisamoto, M. Ohmichi, H. Kurachi et al., "Estrogen induces the Akt-dependent activation of endothelial nitric-oxide synthase in vascular endothelial cells," The Journal of Biological Chemistry, vol. 276, no. 5, pp. 3459-3467, 2001.

[52] E. Nevzati, M. Shafighi, K. D. Bakhtian, H. Treiber, J. Fandino, and A. R. Fathi, "Estrogen induces nitric oxide production via nitric oxide synthase activation in endothelial cells," Acta Neurochirurgica Supplement, vol. 120, pp. 141-145, 2015.

[53] B. M. Melnyk, M. Amaya, L. A. Szalacha, and J. Hoying, "Relationships among perceived wellness culture, healthy lifestyle beliefs, and healthy behaviors in university faculty and staff: implications for practice and future research," Western Journal of Nursing Research, vol. 38, no. 3, pp. 308-324, 2016.

[54] O. Hammig and M. A. Puhan, "How healthy are and behave men? Differences in health status and health behavior between the two sexes in the Canton of Zurich," Praxis, vol. 104, no. 20, pp. 1085-1090, 2015.

[55] S. Y. Ryu, J. Park, S. W. Choi, and M. A. Han, "Associations between socio-demographic characteristics and healthy lifestyles in Korean adults: the result of the 2010 Community Health Survey," Journal of Preventive Medicine and Public Health, vol. 47, no. 2, pp. 113-123, 2014.

[56] M. I. K. von Bothmer and B. Fridlund, "Gender differences in health habits and in motivation for a healthy lifestyle among Swedish university students," Nursing \& Health Sciences, vol. 7, no. 2, pp. 107-118, 2005.

[57] R. S. Barua, J. A. Ambrose, S. Srivastava, M. C. DeVoe, and L.-J. Eales-Reynolds, "Reactive oxygen species are involved in smoking-induced dysfunction of nitric oxide biosynthesis and upregulation of endothelial nitric oxide synthase: an in vitro demonstration in human coronary artery endothelial cells," Circulation, vol. 107, no. 18, pp. 2342-2347, 2003.

[58] R. S. Barua, J. A. Ambrose, L.-J. Eales-Reynolds, M. C. DeVoe, J. G. Zervas, and D. C. Saha, "Dysfunctional endothelial nitric oxide biosynthesis in healthy smokers with impaired endothelium-dependent vasodilatation," Circulation, vol. 104, no. 16, pp. 1905-1910, 2001.

[59] A. Barik, R. K. Rai, A. Gorain, S. Majumdar, and A. Chowdhury, "Socio-economic disparities in tobacco consumption in rural India: evidence from a health and demographic surveillance system," Perspectives in Public Health, 2015.

[60] M. Moradi-Lakeh, C. El Bcheraoui, M. Tuffaha et al., "Tobacco consumption in the Kingdom of Saudi Arabia, 2013: findings from a national survey health promotion and society," $B M C$ Public Health, vol. 15, article 611, 2015.

[61] G. A. Giovino, S. A. Mirza, J. M. Samet et al., “Tobacco use in 3 billion individuals from 16 countries: an analysis of nationally representative cross-sectional household surveys," The Lancet, vol. 380, no. 9842, pp. 668-679, 2012. 


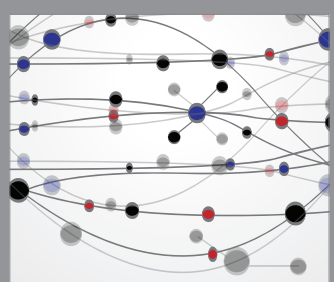

The Scientific World Journal
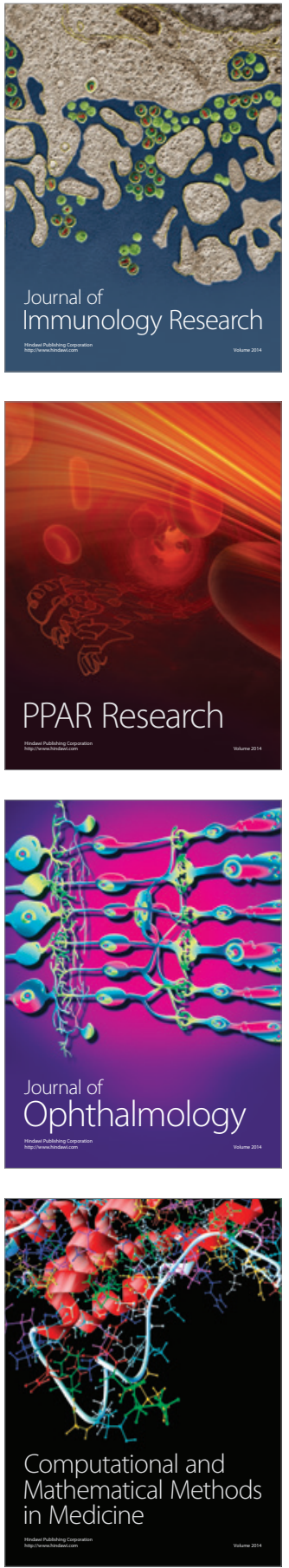

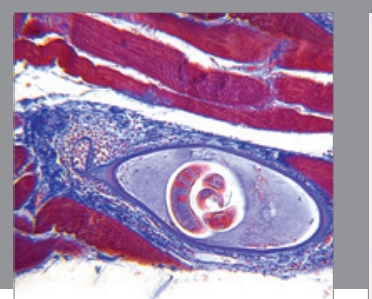

Gastroenterology Research and Practice

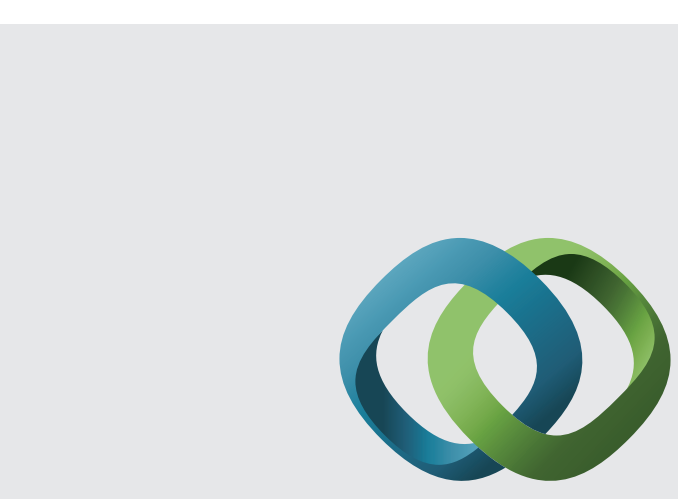

\section{Hindawi}

Submit your manuscripts at

http://www.hindawi.com
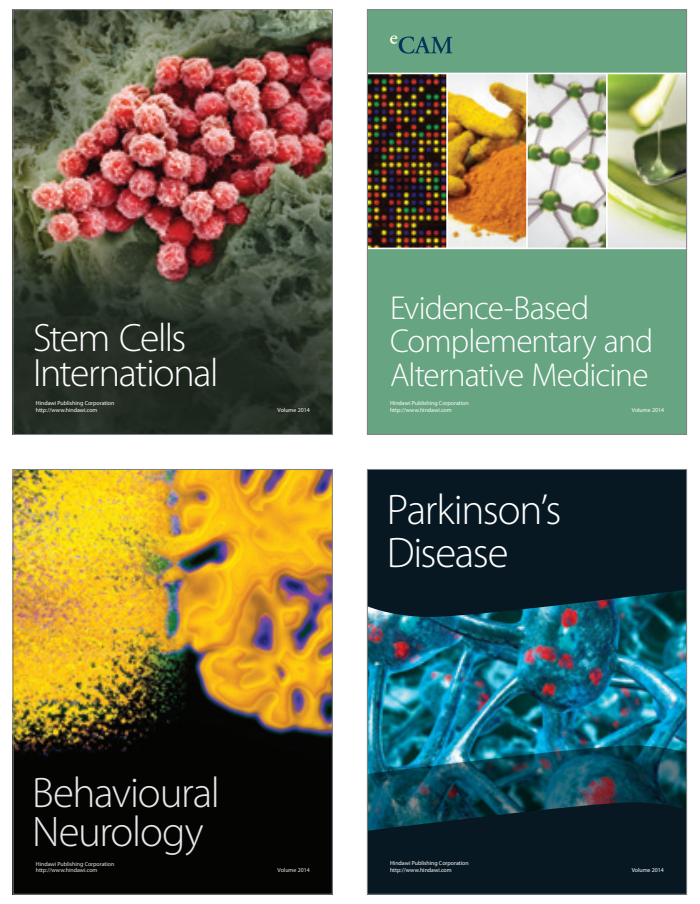
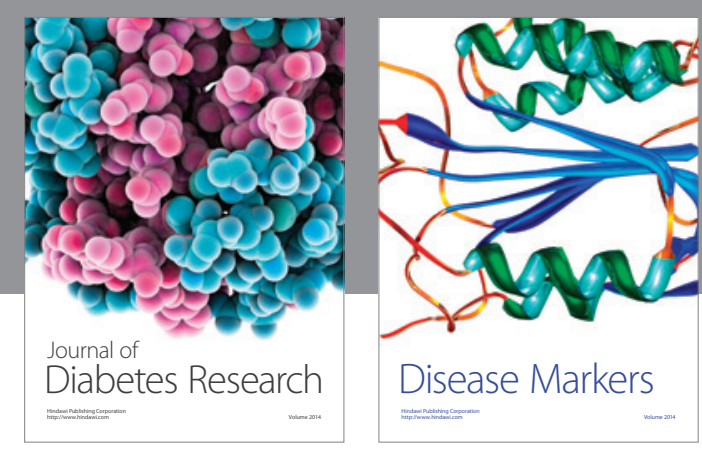

Disease Markers
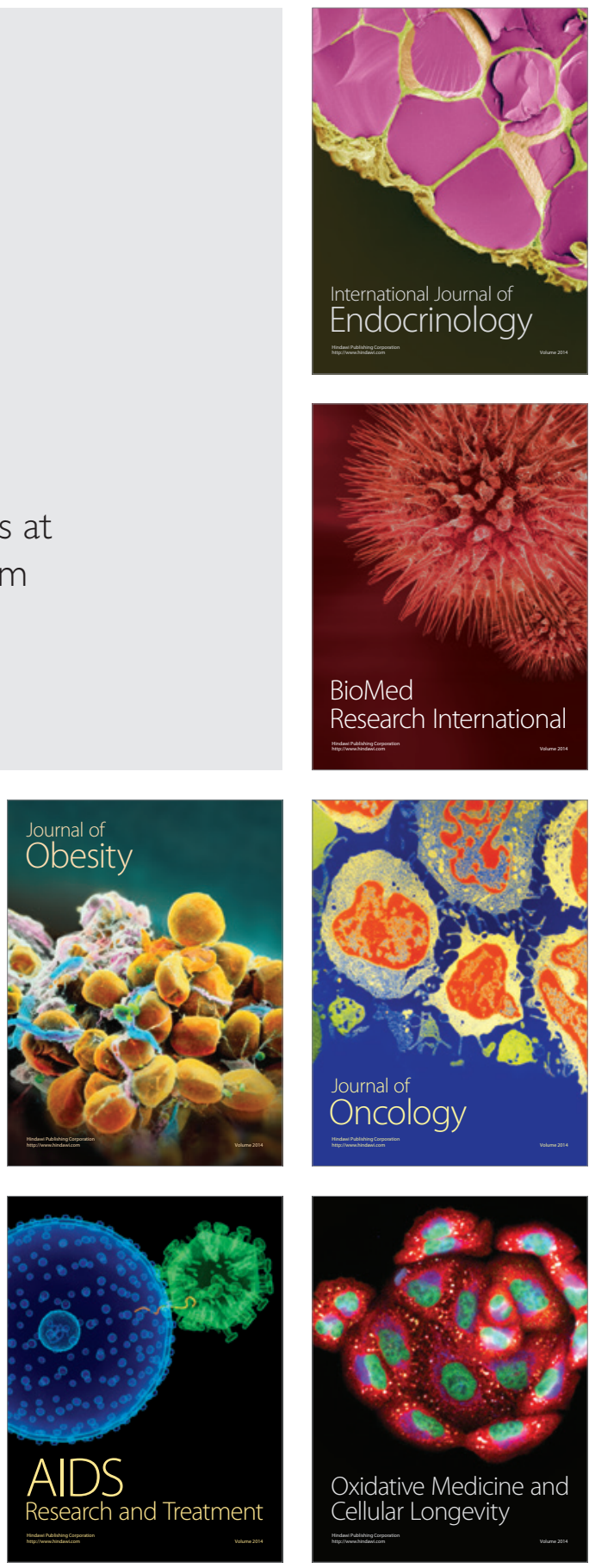